\title{
COMPARATIVE STUDY ON ESTABLISHING LIFE CYCLE ASSESSMENT (LCA) IN BUILDINGS: DRIVERS
}

\author{
AMARASINGHE S.D.I.A. ${ }^{1}$, SOORIGE S.D.A. ${ }^{2} \&$ L DE SILVA 3 \\ 1,2,3 Univerisity of Moratuwa, Colombo, Sri Lanka \\ isuriamarasignhe@gmail.com,ra-isuri@uom.lk, 2sooriged@uom.lk,3lalithds@uom.lk
}

\begin{abstract}
LCA is a method that systematically evaluates environmental impacts attributed to the building by quantifying environmental inputs and outputs over the lifecycle of buildings. LCA facilitates a sophisticated assessment procedure to promote eco-efficient designs to reduce environmental impacts. Although building-related LCAs are well-rooted in developed counties, it is challenging to disclose evidence of LCA application in Sri Lanka as a developing country. Therefore, this study aims to compare drivers that promote the application of LCA in developed countries and Sri Lanka to determine the deviation between two contexts. The qualitative research approach was adopted, and expert interviews were conducted with ten experts from Sri Lanka and nine LCA experts representing developed countries. The results indicated that 'identifying opportunities to improve environmental sustainability,' discovering energy-saving opportunities' etc. are the mostly identified drivers related to developed countries. In contrast, the mostly identified drivers in Sri Lanka were limited to two as 'growing industrial interest to build more green buildings' and 'as a new tool for R\&D'. Initiation of strong government policies and effective incentive mechanisms, rising awareness on LCA, etc. identified as strategies to bridge the deviation between Sri Lanka from developed countries context in the implementation of LCA.
\end{abstract}

Keywords: Buildings; Developed countries; Developing countries; Life Cycle Assessment (LCA), Sri Lanka

\section{Introduction}

The built environment makes a substantial contribution to economic and social development in the modern world (Asif et al., 2007). Contrary, the building sector can be identified as one of the major sources for the environmental repercussions at local, national, and global levels as a consequence of erecting buildings and other forms of improvements (e.g., renovations, reconstructions, etc.) (Kylili et al., 2017). Moreover, building construction activities continue at a fast pace. Thus, society is running under heavy pressure due to the generation of grave ecological issues such as global warming, climate change, natural resource depletion, and waste accumulation (Baccarne et al., 2016). Consequently, there is an imperative need to mitigate these environmental challenges arisen with the escalation of building construction activities (Cabeza et al., 2014). Subsequently, several methods have implemented to address environmental problems. Examples include LCA, Environmental Auditing, Ecological Footprint Calculation, Environmental Impact Assessment (EIA), and so on (Atmaca, 2016; Todd, 2012).

Amongst, tools mentioned above, LCA is an analytical method that systematically investigates the potential environmental impacts attributed to the building by quantifying material usage, energy consumption and environmental releases (i.e., atmospheric emissions, solid waste generation, and waterborne waste) over the lifecycle. LCA enables the quantification of cumulative environmental impacts attached along the entire lifecycle from "cradle to cradle" (Silvestre, et al., 2014). The term "cradle to cradle" refers to the interlinked phases in the entire lifecycle from raw material extraction to disposal.

LCA is recognized as a robust decision-making tool to identify opportunities for environmental improvements (Chau et al., 2015). For instance, Ding (2014) emphasized that LCA has been utilized to promote eco-efficient designs to reduce environmental impacts in the built environment. On the other hand, LCA has been mostly applied in buildings in developed countries such as; Europe, North America, Japan, and Korea (Saunders, et al., 2013). For instance, LCA study was carried out on residential buildings in the United Kingdom (UK), which analyzed the environmental impacts throughout the whole lifecycle. The results disclosed that amongst different lifecycle stages, the operation stage is the major contributor to most environmental impacts (Lawania and Biswas, 2017). However, the application of LCA in the building sector of developing countries is limited (Saunders, et al., 2013). 
When considering Sri Lanka as a developing country, the building constructions would be projected to boom in the coming years with the forthcoming construction projects (Fernando, 2016). With the rapid increase of buildings, Sri Lanka has been facing several different environmental challenges (e.g., pollution, construction waste generation, etc.) (Munasinghe et al., 2017). It has appeared as a need to integrate the concept of LCA for buildings in Sri Lanka to mitigate the increasing environmental impact. Though LCA had well-rooted internationally, it is challenging to disclose evidence on the LCA application in the Sri Lankan building sector. Therefore, this study aims to conduct an in-depth investigation and compression of the driving factors that promote the application of LCA in developed countries and Sri Lanka to determine the deviation of Sri Lanka from the developed countries. Finally, this study provides strategies to bridge the gap between developed countries and Sri Lanka.

\section{Literature Review}

\subsection{DRIVERS IN IMPLEMENTING LCA OF BUILDINGS}

Drivers are the factors that encourage the implementation of the LCA. LCA results could be used to compare the environmental impacts of alternative building materials, to select materials with least environmental impacts (Ortiz-Rodríguez et al., 2010). LCA considers a wide range of environmental impacts categories such as global warming, resource depletion, water depletion, eutrophication, ozone depletion, acidification, eco-toxicity, and so forth (Rebitzer, et al., 2004). Hence, Kutnar and Hill (2015) stated that one of the valuable outcomes of the LCA study is to recognize the 'hot-spots', which are the most significant environmental issues in the lifecycle, where the improvements could be made to get the greatest environmental benefits. Therefore the incorporation of LCA to the early design stage of construction would support in making environmentally-conscious decisions with proper scientific justification. Accordingly, LCA is generally recognized as a decision-making tool to identify opportunities for environmental improvements, which drives the application of LCA to the buildings.

Moreover, Dewulf et al (2009) emphasized that the buildings in developed countries actively contributes to publishing handbooks and organizing workshops on LCA, which could also be recognized as drivers in implementing LCA. There is also a growing interest in constructing green buildings in developed countries to achieve environmental sustainability targets. The construction of green buildings involves a full LCA to evaluate the harmful effects on the environment throughout the entire lifecycle of the building. Consequently, the growing interest in the development of green buildings acts as a strong driver for the adoption of LCA in the building industry in developed countries (Singh et al., 2011). Moreover, Asadollahfardi et al (2015) specify that LCA software applications have introduced in recent times that make it easy to implement LCA buildings. Likewise, many studies have divulged various drivers that encourage the implementation of LCA for buildings. The summary of the literature findings of the drivers is tabulated in Table 1 with relevant references.

Table 1: Drivers for LCA implantation to the building sector

\begin{tabular}{lll}
\hline No & \multicolumn{1}{c}{ Drivers } & \multicolumn{1}{c}{ Ref. Code } \\
\hline 1 & To recognize opportunities to improve environmental sustainability & 2,4 \\
2 & To introduce environmental targets and benchmarks for buildings & 4 \\
3 & To discover energy-saving opportunities & 2,3 \\
4 & Growing industrial interest to erect more green buildings & 1,2 \\
5 & Top management pressure for LCA implementation & 1 \\
6 & To meet eco-labeling requirements & $1,2,3,4$ \\
7 & As a novel tool for Research and Development (R\&D) & 1 \\
8 & As an environmental law or political pressure & 1,3 \\
9 & Due to the LCA application from other competing companies & 1 \\
10 & Growing industrial interest in applying LCA for the built environment & 1 \\
11 & To obtain marketing benefits & 4 \\
\hline
\end{tabular}

Source: (Adapted from 1- Frankl and Rubik, 2000; 2- Lewis and Demmers, 1996; 3- McManus and Taylor, 2018; 4- Bribián et al., 2009) 


\section{Research Method}

Lichtman (2010) highlighted that qualitative research methodology uses to capture a deeper understanding of particular problem domains by investigating experts' knowledge and experiences. Qualitative research involves collecting and analyzing non-numerical data to understand concepts, opinions, or experiences. Furthermore, as stated by Lapan et al (2012), a qualitative research method could be utilized to conduct in-depth research using a small sample size. LCA applications in the building sector not popular in Sri Lanka yet. Hence, only a very few LCA experts have found both practical exposure and knowledge in Sri Lanka. To exploring this novel phenomenon of the LCA concept, the qualitative approach could be identified as the most appropriate method by exploring LCA experts' knowledge. Moreover, this research focuses on investigating the driving factors that promote the application of LCA in developed countries and Sri Lanka to determine the strategies to establish LCA in the Sri Lankan building sector, which generates a high volume of qualitative data. Semi-structured expert interviews were carried out with the help of a snowball sampling technique. Moreover, expert interviews comprise ten (10) Sri Lankan LCA experts and nine (9) experts representing developed countries ( Canada, , UK United States of America (USA ), and Australia), and outcomes were analyzed using content analysis to develop the findings and conclusions. The profile of the interviewees is shown in Table 2.

Table 2: Profile of the Interviewees

\begin{tabular}{clcc}
\hline $\begin{array}{c}\text { Type of } \\
\text { Interviewees }\end{array}$ & \multicolumn{1}{c}{ Designation } & $\begin{array}{c}\text { Reference } \\
\text { Code }\end{array}$ & $\begin{array}{c}\text { LCA } \\
\text { Experience }\end{array}$ \\
\hline & General Manager -Sustainability & SL1 & 11 years \\
& Senior Lecturer & SL2 & 10 years \\
& Manager- Sustainability Assurance & SL3 & 8 years \\
Interviewees & Director -Sustainability & SL4 & 17 years \\
from Sri Lankan & Chief Executive Officer & SL5 & 12 years \\
& Chief Executive Officer & SL6 & 14 years \\
& Engineer & SL7 & 5 years \\
& Senior Lecturer & SL8 & 14 years \\
& Professor -Environmental Science & SL9 & 5 years \\
& Consultant -Sustainability & SL10 & 6 years \\
\hline & Professor -Sustainable Construction & DC1 & 17 years \\
Interviewees & Senior Lecturer & DC2 & 10 years \\
from Developed & Researcher - LCA & DC3 & 4 years \\
Countries & Engineer - LCA & DC4 & 3 years \\
& Professor -Environmental Management & DC5 & 19 years \\
& Engineer & DC6 & 14 years \\
& Researcher & DC7 & 17 years \\
& Professor & DC8 & 5 years \\
& & DC9 & 16 years \\
\hline
\end{tabular}

\section{Data Analysis and Research Findings}

\subsection{DRIVERS IN IMPLEMENTING LCA OF BUILDINGS IN DEVELOPED COUNTRIES}

Driving factors which motivate the adoption of LCA in developed countries were critically reviewed, to integrate those practices to the Sri Lankan buildings and to inspire the Sri Lankan building sector to adopt LCA. Respondents representing the developed countries were presented with identified drivers (see Table 1) from the literature synthesis and were asked to identify drivers applicable to developed countries with the help of their knowledge and experience.

From the expert interview findings, it was revealed that drivers such as 'recognize opportunities to improve the environmental sustainability, 'discover energy-saving opportunities', 'growing industrial interest to erect more green buildings', 'to meet eco-labeling requirements', 'growing industrial interest on applying LCA for the built environment' and 'to obtain marketing benefits' are the drivers 
which have been agreed by all respondents. DC2 stated that "LCA has been used to improve environmental performances by identifying ecological hotspots throughout the building lifespan due to the global movement towards achieving a more sustainable environment". Besides, interview findings highlighted that LCA has been driven to the buildings as an environmental communication tool to attract green-conscious clients.

It has been disclosed that the drivers such as 'due to the LCA application from other competing companies' and 'to acquire subsidies on environmental impact reduction' could be identified as drivers that are reported by eight out of nine respondents. $\mathrm{DC}_{4}$ emphasized, "provision of lowinterest loans and tax benefits for environmental friendly constructions drives the LCA implementation into the Canadian buildings." It appears that government incentives increase the willingness to conduct LCA of buildings. The driving factor of "introduce environmental targets and benchmarks for buildings' is another driver reported by seven out of nine respondents.

Additionally, a very limited number of respondents identified 'top management pressure' as a driver for implanting LCA of buildings. Only two out of nine respondents have mentioned "as a novel instrument for R\&D' as a driver. LCA is no more a novel instrument for Canada, UK, and the USA. The driver of 'as environmental law or political pressure' does not apply to the developed countries, as it was not mentioned by any of the respondents. LCA is a voluntary approach utilized by practitioners to make accurate decisions rather than an adapted approach due to regulatory or political pressure.

In addition to the drivers identified from the literature review, interviewees mentioned new drivers such as, 'awareness of the general public on LCA concept', 'preparation of maintenance, retrofitting, carbon-neutral and rehabilitation tools by using LCA data', ' to improve recognition', 'empirically proved benefits of conducting LCA' and 'due to the introduction of Simplified LCA method', which applies to the developed countries.

\subsection{DRIVERS IN IMPLEMENTING LCA OF BUILDINGS IN SRI LANKA}

It is very critical to understand the drivers, which encourage LCA application in Sri Lanka to enhance the existing level of application furthermore. Thenrespondents representing Sri Lanka were presented with identified drivers (see Table 1) from the literature synthesis and were asked to identify drivers applicable to Sri Lanka with the help of their knowledge and experience.

From interview findings, it was vivid that drivers such as 'growing industrial interest to erect more green buildings' and 'as a novel tool for R\&D', identified by all interviewees. Furthermore, SL1 mentioned that "the rapid increase of buildings, brought pressure on environmental protection and resource conservation in Sri Lanka. Subsequently, there is a rising interest in developing green buildings. Green building constructions require an integrated building LCA, which considers all environmental impacts throughout the entire building lifecycle. Also, the integration of LCA with the LEED certification process provides a strong foundation for the adoption of LCA of buildings" As per the views of SL9, "there is a trend in applying LCA as a novel instrument for eco-innovation, which drives LCA of buildings. Research activities on LCA are also increasing among the researchers to support eco-innovations in Sri Lanka."

It was discovered that the drivers such as 'to recognize opportunities to improve the environmental sustainability', 'to meet eco-labeling requirements' and 'discover energy-saving opportunities' remain as critical drivers to its adoption in Sri Lanka. Supportively SL5 elaborated that " $L C A$ results could be used to compare the environmental impacts of alternative materials that could be used during the building construction process. Hence, LCA is driven to the buildings by integrating proactive environmental concerns." In addition to the above, interviewees stated that the building sector had 
been criticized as one of the highest energy-consuming sectors. Hence LCA drives to recognize energy -saving opportunities through energy reductions during the entire lifecycle.

As per the opinion of six experts out of ten, 'growing industrial interest on applying LCA for the built environment' and 'to obtain marketing benefits' are perceived to have some degree of importance for implementing LCA. Besides, the driving factor of 'due to the LCA application from other competing companies' was the factor which was rarely highlighted by the experts. Conversely, drivers such as 'top management pressure', 'as environmental law or political pressure', and 'acquire subsidies on environmental impact reduction' do not apply to the Sri Lankan context, as none of the interviewees agreed for these as drivers. According to SL3, "top management and political pressure cannot be seen within the Sri Lankan building sector due to the lack of awareness of LCA." SL6 emphasized that "lack of advocatory incentives play a main role in the Sri Lankan building sector to hinder the adoption of LCA."

Additionally, 'Sustainable Public Procurement (SPP) for building products', 'ISO 14001 certification', 'National Green Reporting System of Sri Lanka' could be identified as new drivers, which were added by the interviewees in addition to the literature findings.

\subsection{COMPARISON BETWEEN DRIVERS IN IMPLEMENTING LCA OF BUILDINGS IN DEVELOPED COUNTRIES AND SRI LANKA}

Section 4.1 and section 4.2 respectively discuss the interview findings on drivers on the implementation of LCA for developed countries and Sri Lanka. This section addresses the similarities and dissimilarities between the two contexts mentioned above to determine the deviation of Sri Lanka from the developed countries.

When considering the similarities between the two contexts, it could be identified that drivers such as 'to recognize opportunities to improve the environmental sustainability', discover energy-saving opportunities, 'growing industrial interest to erect more green buildings' and 'to meet eco-labeling requirements' common for both contexts. All experts in the mindset that the aforesaid factors become drivers for both contexts. Nevertheless, when it comes to the Sri Lankan context, LCA has been driven to the buildings by focusing on calculating the global warming potential of the building lifecycle. However, in developed countries, LCA has been focused on multiple impact categories such as global warming, acidification, eutrophication, ozone depletion, etc. rather than one impact category.

The driver of 'top management pressure to implement LCA' and 'as environmental law or political pressure' cannot be identified as drivers for both contexts. According to DC6 "government regulations and policies are making the enabling environment by directing towards "life-cycle accountability;" building owner is responsible for direct construction impacts, as well as for the indirect impacts related to material usage, transportation, and disposal. Stakeholders in building and construction are applying LCA as a voluntary practice to represent the contribution and strong efforts to construct sustainable buildings other than due to environmental or political pressure." Further, it was confirmed by SL3 mentioning, "LCA cannot be regulated, it has to be done voluntarily."

Dissimilarities also could be found between the two contexts. LCA has been driven to the Sri Lankan buildings as a novel instrument for R\&D, contrary when it comes to the UK, USA, and Canadian, LCA is not a novel instrument. In the developed countries, the driver of 'due to the LCA application from other competing companies' is highly voted. Nevertheless, it has not become a highly voted driver for Sri Lanka. According to SL2, "awareness on LCA is relatively low and demand for LCA is not derived from the building sector. The life cycle concept is not yet being considered when designing buildings in Sri Lanka." Hence, the driving factor of 'growing industrial interest on applying LCA for the built environment' is not a highly voted driver in Sri Lanka, even though it has been highlighted as one of 
the highly voted drivers in developed countries. 'To obtain marketing benefits' and 'to acquire subsidies on environmental impact reduction' not become drivers to implement LCA of buildings in Sri Lanka. Nevertheless, these were identified as drivers in developed countries.

\subsection{STRATEGIES TO ENHANCE THE LCA APPLICATIONS IN SRI LANKA}

This section presents appropriate strategies to enhance the LCA application in Sri Lanka.

- Initiation of strong governmental regulations and effective incentive mechanisms SL2 stated that " it is more critical to implement country-level emission reduction objectives and energy-saving goals for the buildings through the introduction of building regulations, acts, policies, codes, and standards with the use of LCA." Interviewees highlighted that the government could provide rewards and incentives to encourage sustainability initiatives within the Sri Lankan building sector. Incentives in the sort of, insurance premium reductions, tax reductions, green loans as well as rewards can be awarded to appraise the adoption of sustainable and green building practices. With the encouragement of sustainability initiatives, it will automatically increase the LCA practice within the building industry.

\section{- $\quad$ Rising awareness}

LCA of buildings in Sri Lanka is evolving and still immature. Stakeholders in the Sri Lankan building sector are unaware of the potential financial and non-financial benefits of applying LCA. Hence, rising stakeholders' awareness is an effective way of popularizing and promoting the LCA within the Sri Lankan building sector, as it may help to convert stakeholders' attitudes into demand conditions. SL2 and DC8 emphasized that it is essential to make construction professionals, investors, and clients aware of LCA by conducting awareness-raising programs. Supportively, SL9 highlighted that "the LCA concept needs to promote within the building sector by emphasizing its benefits, then it will be automatically applied within the industry."

\section{- Encourage to conduct LCA based research activities}

Professionals in the field of the building sector are not interested in research activities on LCA. Therefore, SL9 mentioned that it is important to prioritize research activities by providing funding for LCA-based research. Consequently, researchers could then share evidence-based, accurate information with industry professionals. This will result in a higher level of LCA applications in the future than in the current situation. SL8 supported by stating, "universities in collaborating with the government should allocate sufficient grants for research activities."

\section{- Integrate LCA concept with undergraduate and postgraduate curriculum}

As per the views of SL5, SL6, and DC9 it is necessary to integrate LCA with undergraduate and postgraduate curriculums to popularize LCA among future professionals. As a result of that, the LCA concept automatically receives a prominent place in the building sector.

\section{- Development of regional specific LCA databases}

The availability of LCA software and databases could be identified as one of the most important requirements for enhancing the application of LCA by proving LCA data to ensure successful application in the building sector. Therefore, SL 3 sated that action needs to be taken to develop a user-friendly LCA database.

Above identified strategies could be utilized to enhance the LCA application in the Sri Lankan construction industry

\section{Conclusions}

The findings of the study revealed that LCA is a well-established concept in developed countries, although it has not yet penetrated to the Sri Lankan building sector. Hence, drivers in implementing 
LCA in developed countries were compared with Sri Lanka to determine the deviation of Sri Lanka from the developed countries. Drivers such as 'recognize opportunities to improve the environmental sustainability, 'discover energy-saving opportunities', 'growing industrial interest to erect more green buildings', 'to meet eco-labeling requirements', 'growing industrial interest on applying LCA for the built environment' and 'to obtain marketing benefits' were the most identified driving factors related to the context of developed countries. In contrast to that, only two drivers, such as 'growing industrial interest to erect more green buildings' and 'as a novel tool for R\&D” were the most identified in the Sri Lankan context. Moreover, LCA has been driven to the Sri Lankan buildings as a novel instrument for R\&D, but for the UK, USA, and Canadian context, LCA is not a novel instrument. Further, the drivers of 'top management pressure to implement LCA' and 'as environmental law or political pressure' cannot be identified as drivers for both contexts.Furthermore, it could be mentioned that 'recognize opportunities to improve the environmental sustainability, 'growing industrial interest to erect more green buildings', 'to meet eco-labeling requirements', 'growing industrial interest on applying LCA for the built environment' and 'to obtain marketing benefits' were become drivers to the developed countries which were identified by all respondents due to the well establishment of LCA of buildings. However, those are not drivers in Sri Lanka since it is in the inception stage of applying LCA of buildings. Initiation of strong government policies and effective incentive mechanisms, rising awareness on LCA, sponsoring to perform more LCA related research activities, and combine LCA into undergraduate and postgraduate curriculums could be identified as strategies used to bridge the deviation between developed countries context from Sri Lanka context in the implementation of LCA. Recognized strategies can be used to extend the application of LCA by gaining benefits for the Sri Lankan building sector. The scope of the research was narrowed to compare the LCA of buildings in developed countries and Sri Lanka and developing countries (i.e. Sri Lanka) predominantly represented the perception of professionals whereas developed countries predominantly represented the perception of academics. This might be due to the difficulties in sampling.

\section{References}

Asadollahfardi, G., Asadi, M., and Karimi, S: 2015, Life-cycle assessment of construction in a developing country, Environmental quality management, 24(4), 11-21

Asif, M., Muneer, T., and Kelley, R: 2007, Life cycle assessment: A case study of a dwelling home in Scotland, Building and environment, 42(3), 1391-1394

Atmaca, A: 2016, Life cycle assessment and cost analysis of residential buildings in south east of Turkey: part 1-review and methodology, The international journal of life cycle assessment, 21(6), 831-846

Baccarne, B., Logghe, S., Schuurman, D., and Marez, L. D: 2016, Governing quintuple helix innovation: Urban living labs and socio-ecological entrepreneurship, Technology innovation management review, 6(3), 22-30

Bribián, I. Z., Usón, A. A., and Scarpellini, S: 2009, Life cycle assessment in buildings: State-of-the-art and simplified LCA methodology as a complement for building certification, Building and environment, 44(12), 2510-2520

Cabeza, L. F., Rincón, L., Vilariño, V., Pérez, G., and Castell, A: 2014, Life Cycle Assessment (LCA) and Life Cycle Energy Analysis (LCEA) of buildings and the building sector: A review, Renewable and sustainable energy reviews, 29, 394-416

Chau, C., Leung, T., and Ng, W: 2015, Corrigendum to a review on life cycle assessment, life cycle energy assessment and life cycle carbon emissions assessment on buildings, Applied energy, 158, 656

Dewulf, J. V. D., Vorst, G. V., Versele, N. undefined, Janssens, A. undefined, and Langenhove, H: 2009, Quantification of the impact of the end-of-life scenario on the overall resource consumption for a dwelling house, Resources, conservation and recycling, 53(4), 231-236

Ding, G: 2014, Life cycle assessment (LCA) of sustainable building materials: an overview, Eco-efficient construction and building materials, 38-62

Fernando, L.: 2016, "Project Megapolis explained - Colombo, Gampaha, Kalutara to merge - Sri Lanka" Available from http://newsfirst.lk/english/2016/o1/project-megapolis-explained-colombo-gampaha-kalutara-to-merge/126380. (2016, January 26)

Frankl, P., and Rubik, F: 2000, A static perspective on LCA applications - survey results, Life cycle assessment in industry and business, $53^{-101}$

Kutnar, A., and Hill, C: 2015, End of life scenarios and the carbon footprint of wood cladding, In The carbon footprint handbook (pp. 102-117) CRC Pres 
Kylili, A., Ilic, M., and Fokaides, P. A: 2017, Whole-building Life Cycle Assessment (LCA) of a passive house of the subtropical climatic zone, Resources, conservation and recycling, 116, 169-177

Lapan, S. D., Quartaroli, M. T., and Riemer, F. J: 2012, Qualitative research: an introduction to methods and designs, San Francisco: Jossey-Bass

Lawania, K., and Biswas, W. K: 2017, application of life cycle assessment approach to deliver low carbon houses at regional level in Western Australia, The international journal of life cycle assessment, 23(2), 204-224

Lewis, H., and Demmers, M: 1996, Life cycle assessment and environmental management, Australasian journal of environmental management, 3(2), 110-123

Lichtman, M: 2010, Qualitative research in education: A user's guide, Los Angeles: Sage

Mcmanus, M. C., and Taylor, C. M: 2018, Greenhouse gas balances of bioenergy systems: The role of life cycle assessment. Greenhouse gases balances of bioenergy systems, 29-41

Munasinghe, M., Deraniyagala, Y., Dassanayake, N., and Karunarathna, H: 2017, Economic, social and environmental impacts and overall sustainability of the tea sector in Sri Lanka, Sustainable production and consumption, 12, 155-169

Ortiz Rodríguez, F. and Román Collazo, C.A., 2010. Disciplina morfofisiología como alternativa de integración curricular en la enseñanza de la medicina. Revista Habanera de Ciencias Médicas, 9(2), pp.272-279

Rebitzer, G., Ekvall, T., Frischknecht, R., Hunkeler, H., Norris, G., Rydberg, T., and Pennington, D. W: 2004, Life cycle assessment: Part 1: Framework, goal and scope definition, inventory analysis, and applications, Environment international, 3O(5), 701-720

Saunders, C. L., Landis, A. E., Mecca, L. P., Jones, A. K., Schaefer, L. A., and Bilec, M. M: 2013, Analyzing the practice of life cycle assessment, Journal of industrial ecology

Silvestre, J. D., de Brito, J., \& Pinheiro, M. D. (2014, April). Life-cycle impact 'cradle to cradle'of building assemblies. In Proceedings of the Institution of Civil Engineers-Engineering Sustainability (Vol. 167, No. 2, pp. 53-63). Thomas Telford Ltd.

Singh, A., Berghorn, G., Joshi, S., and Syal, M: 2011, Review of life-cycle assessment applications in building construction, Journal of architectural engineering, 17(1), 15-23

Todd, J. A: 2012, Buildings, systems thinking, and life cycle assessment. Life Cycle Assessment Handbook, 311-328.

Yin, R. K: 2016, Qualitative research from start to finish, New York, NY: Guilford Press 